\title{
Assessment of autonomic function in children using cell telephone
}

\author{
Ahmed K Kamal* \\ College of Engineering, MET Department, Tennessee Technological University, USA
}

\begin{abstract}
Objectives: The main objective of this work is to study the effect of using cell telephone on autonomic nervous system of 20 children before, during and after using their cell telephones.

Methods: Electrocardiograms of twenty normal children (age 7-12 years) were measured and recorded before, during and after using normal cell telephone for 15 minutes, followed by a 15 minutes recovery period after using cell telephone.

Results: The results clearly indicate that cell telephone radiation induced high fluctuations in power spectra of heart rate variability signals specially in the band of 8 s to $80 \mathrm{~s}(0.0125 \mathrm{~Hz}$ to $0.125 \mathrm{~Hz})$ which is related to the thermoregulatory control activity. Examining the power spectra of heart rate variability of recovery period (after 15 minutes using cell telephone) shows that the change of power spectra of heart rate variability signal during cell telephone exposure is not permanent.

Conclusions: The analysis of power spectra of heart rate variability signals of 20 normal children to assess the autonomic nervous system before, during and after using cell telephone seems useful to indicate the interaction of pulsed microwaves of the cell telphone with cardiovascular system, autonomic function and body control mechanism.
\end{abstract}

\section{Introduction}

One of the most interesting and widely recognized biological effects on microwaves is microwaves induced thermoelastic expansion [1]. A theoretical model based on thermoelastic expansion has been developed for brain spheres that are exposed to pulsed microwave [2]. This theory describes acoustic waves (with parameters of frequency, pressure and displacement) generated in the head as function of absorbed microwave energies in the brain. Actually, several studies reported successful use of pulsed microwaves to induce acoustic pressure waves in the brain [2-4]. Another studies of teratological effects concentrated on pulsed magnetic fields on chick embryos [5-7]. A typical example of these studies is reported by Koch and Koch [7]. They investigated the influence of pulsed magnetic field on chick teratology. In addition to 500 us pulse repeated at $100 \mathrm{~Hz}$ which was used by Berman et al. [6], Koch and Koch [7] used a 50us pulse with repetition rate at 33, 50, 1000 and $10000 \mathrm{~Hz}$ respectively. The results of these studies showed the effect of pulsed magnetic field on check embryos. However, exposures to electromagnetic fields and microwaves have been reported to affect the cardiovascular system [8,9]. Investigation of cardiovascular changes during or after exposure to microwave irradiation produced by other sources have not been reported. This study investigates the effect of cell telephone radiation on heart rate variability (HRV) signals in normal children aged (7-12 years). Normally, the heart rate variability signal is affected by respiratory, blood pressure and thermal stimuli $[10,11]$. These stimuli are mediated via autonomic nervous system (sympathetic and parasympathetic) to sinuatrial node (SAN) of the heart causing the heart variation [12,13]. Recent studies [14-16] show the effect of radiation specially cell telephone on skin temperature, cognitive function of the brain and human sleep. The effect of pulsed microwave power specially, on autonomic function is not investigated specially its effect on cardiovascular body control mechanisms. This work presents the effect of cell telphone microwave energy on the body control mechanism of children manifested by auto power spectrum of HRV body signals before, during and after cell telephone exposure.

\section{Methods and children methods}

\section{Children}

These experiments used 20 children aged $(8 \pm 3.5)$ were carried out, at Neurology Center with collaboration of Electrical and Computer Engineering Department at Johns Hopkins University on summer 2012. We comply fully with regulations and requirements including approval of ethical committee and approval of guardians of the children before experimental procedure, the study was performed at Johns Hopkins university hospital, Baltimore, Maryland, USA, over more than one year period. The study group of patients was composed of 20 healthy children $(8 \pm 3.5)$ years and were not taking medication. All cases routine physical examination, a 12 lead surface electrocardiographs, routine biochemistry tests (liver and renal function tests), serum electrolytes, basic hematological parameters were obtained and none of the cases had any evidence of cardiovascular or non-cardiovascular disease. None of children had clinical signs of autonomic dysfunction, history of myocardial infraction, arterial hypertension, diabetes or pulmonary disease. The subjects during the study used no drugs that

Correspondence to: Dr. Ahmed K Kamal, College of Engineering, MET Department, Tennessee Technological University PO Box 5003, Cookeville, TN 38505, USA, E-mail: akamal@tntech.edu

Key words: autonomic function, auto power spectrum and heart rate variability signal

Received: July 03, 2016; Accepted: August 17, 2016; Published: August 19, 2016 
could affect the HRV parameters. Therefore, the final group consisted of 20 healthy children (mean $8 \pm 3.5$ years). All guardians of children agreed to participate in the research prior to their inclusion in the study and the consent of ethical committee was obtained and approved the study protocol. With each subject sitting on chair and physiological measuring devices are connected. The ECG is taken from wrists and the ankle (lead II) for 15 min before using the cell telephone. Then was asked to talk to friend using his cell telephone for $15 \mathrm{~min}$. Then, we asked the subject to rest for another 15 after using his cell telephone. All measurements for ECG before using cell telephone, during using cell telephone and after using cell telephone are measured, recorded and interfaced to laptop PC and stored in CD.

The ECGs were recorded onto FM recorder at speed $4.75 \mathrm{~cm} / \mathrm{sec}$ and played back at the same speed for analysis of HRV signal for 15 minutes before exposure, 20 minutes during cell telphone exposure and 15 minutes during recovery period after exposure. The last 15 minutes of each session were utilized for analysis of HRV signals. The ECGs were band pass filtered between $0.01 \mathrm{~Hz}$ to $100 \mathrm{~Hz}$ and interfaced to Laptop with software package prepared by the author to detect $\mathrm{R}$ wave of ECG and then measure the time between successive $R$ waves $(T n, T n+1, T n+2$ etc) which called RR intervals. This RR interval time is converted to a voltage which is directly proportional to that time. This voltage is connected to the next $\mathrm{R}$ wave i.e., the output voltage is proportional to nth interval during $\mathrm{n}+1$ th $R R$ interval. The reconstructed voltage signal as shown in Figure 1 may now place as HRV signals and can be directed to Laptop to obtain the auto-power spectra of HRV signals using autoRegressive Moving Average package prepared by the author.

The experimental procedure here in this paper is based on measurement of ECGs and derived HRV signals of children using cell telephone and showed in Figure 1. Simultaneously, all signals measured (ECG, HRV) for microwave pulses at $1.655 \mathrm{GHz}$ were fed to the spectrum analyzer or Pentium PC such that both time series of HRV signals and auto-power spectrum domain could be obtained before, during and after the exposure of microwave pulses at $1.655 \mathrm{GHz}$. The difference in the low frequency spectrum energy before, during and after exposure to cell telephone radiation between the 20 children was analyzed and considered statistically significant using one way analysis of variance with repeated measures $(P>0.05)$.

\section{Results}

The mean heart rate for children before experiments was 90

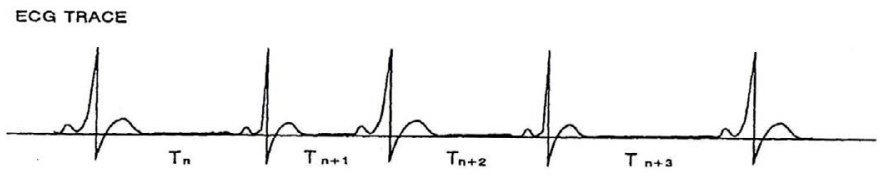

EVENT SEQUENCE
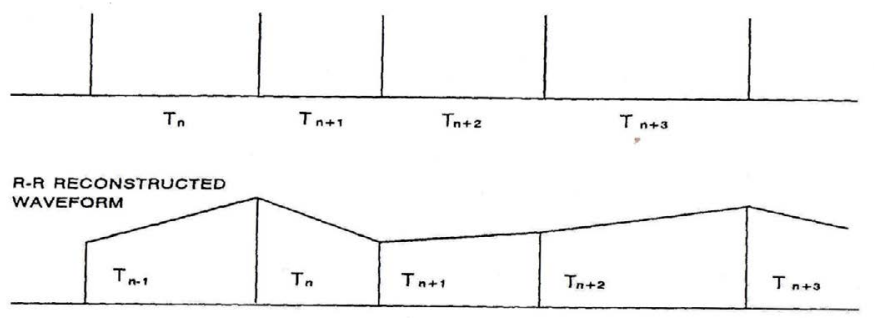

Figure 1. Generation of Heart Rate Variability signal (HRV) derived from Electrocardiogram (ECG). beats/min, during experiments was 120 beats/min and after was 100 beats/min. Table 1 shows the mean heart rate and its standard error of mean before, during and after experiments. The HRV signals were sampled at $400 \mathrm{~ms}$ (frequency is $2.5 \mathrm{~Hz}$ ) and the bandwidth of HRV signal does not exceed $0.5 \mathrm{HZ}$ ) and then filtered by low pass filter to prevent aliasing, then auto-regressive moving average method (ARMA) was applied to these signals to produce the power spectra before, during and after using the cell telephone. Figure 3 shows the average power spectra of HRV signals for 20 children before the experiments and it is clear no distinct peaks in power spectra. Figure 4 shows the average power spectra power spectrum of HRV signals during using cell telephone with significant peak near $0.033 \mathrm{~Hz}$ which represents the thermoregulatory oscillation of thermal body oscillation [1-13]. Figure 5 illustrates the average power spectrum of HRV signals after 15 minutes recovery from microwave exposure. The power spectra of Figure 5 exhibits no significant oscillations during recovery period. The difference in the low frequency spectral energy in auto power spectra before, during and after exposure to microwave irradiation between the 20 children was analyzed by nonpaired student's t test. Differences were considered statistically significant at $\mathrm{p}<0.05$.

\section{Discussion}

This study is the first study to the author's best knowledge to report on low frequency oscillations exist in the power spectra of HRV of young children exposed to cell telephone microwaves irradiation. Other studies [1-4] examined the experimental observation on electrical events that occur along the auditory pathways in response to pulsed modulated microwave stimulation. Also, intensive investigation of possible biological effect of magnetic field are reported by [5-10]. Comparing Figure 2 with Figure 3, it is clear the rising power amplitude of the auto-power spectrum of HRV signal during exposure to the pulsed microwave irradiation using cell telephone specially the appearance of distinct peak at nearly $0.033 \mathrm{~Hz}$ which lies in the frequency band of 0.033 $\mathrm{Hz} \tilde{\mathrm{n}} 0.125 \mathrm{~Hz}$ as shown in Figure 3. This frequency $(0.033 \mathrm{~Hz})$ distinct

Table 1. Mean heart rate and \pm SEM before, during and after experiments.

\begin{tabular}{|l|c|c|}
\hline & $\begin{array}{c}\text { Mean Heart rate } \\
\text { (beats } / \text { min) }\end{array}$ & $\begin{array}{c}\text { Standard Error of Mean } \\
( \pm \text { SEM) }\end{array}$ \\
\hline Before Experiments & 90 & \pm 7 \\
\hline During Experiments & 120 & \pm 17 \\
\hline After Experiments & 100 & \pm 6 \\
\hline
\end{tabular}

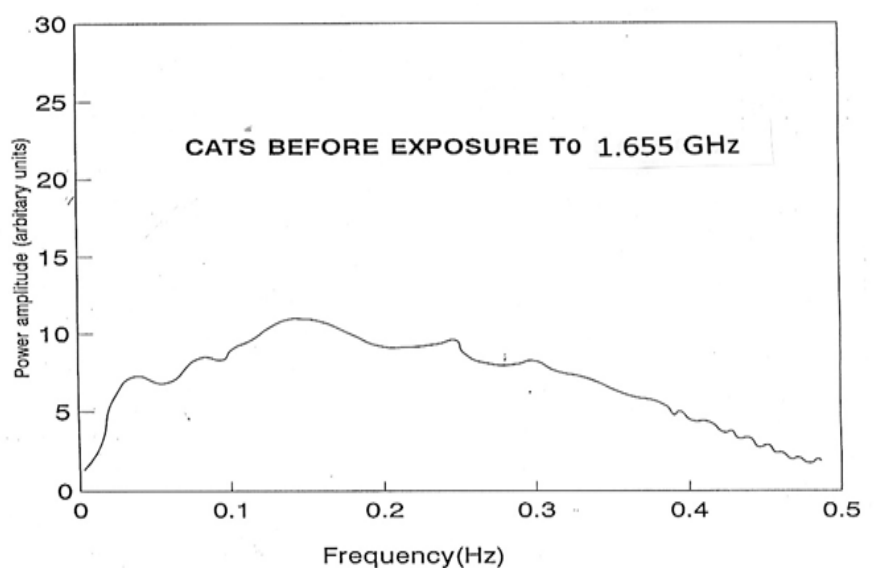

Figure 2. Average Auto-power Spectrum of HRV signals from 20 children before using cell telephone. 


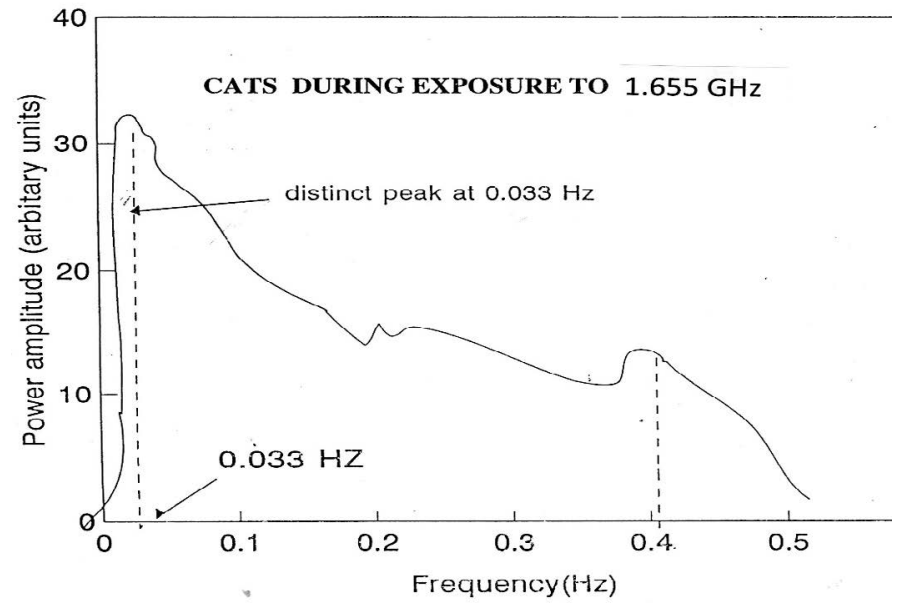

Figure 3. Average Auto-power Spectrum of HRV signals from 20 children during using cell telephone.

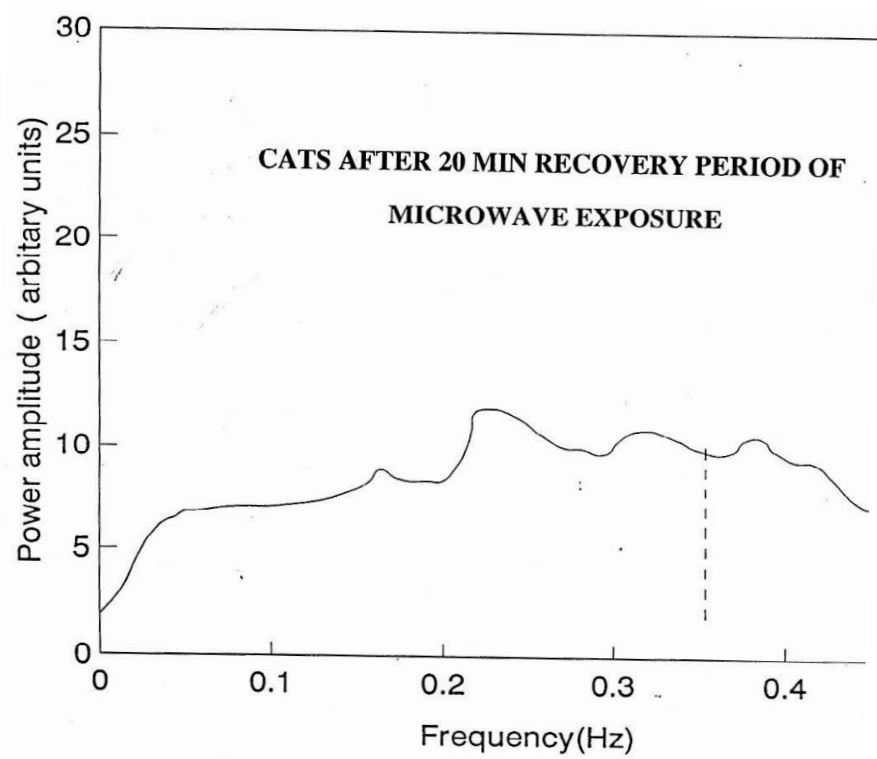

Figure 4. Average Auto-power Spectrum of HRV signals from 20 children after using cell telephone.

peak is usually referred to thermo- regulatory control oscillations [811]. One possible physiological interpretation of increasing power amplitude of auto-power spectrum of HRV signals in the band 0.0125$0.125 \mathrm{~Hz}$ after exposure to microwave energy at $1.655 \mathrm{GHz}$ is as fellow: When microwave irradiation impinges on the head of children, a portion of the absorbed energy is converted into heat which produces a small but rapid rise in temperature in cranial tissues $[3,4]$. This rise in temperature in very short time may affect the body control centers and produces thermo-regulatory oscillations where the autonomic nervous system mediated these oscillations to sinuatrial node (SAN) of the heart and appeared as peak at nearly $0.033 \mathrm{~Hz}$ in the power spectrum of HRV signal during exposure to microwave irradiation as shown in Figure 4. Actually, this pulsed microwave irradiation may stimulate the body control centers of the brain including the brain stem and hypothalamus in the brain $[12,14]$ and entrain the auto-power spectrum of HRV signal with thermo-regulatory control oscillations [14-19]. It seems that as shown in Figure 3 that the power spectrum of HRV signal of cats exposed to pulsed microwave energy is mostly influences by
$0.033 \mathrm{~Hz}$ distinct peak which is related to vasomotor thermal activity indicating the heating effect of pulsed energy on the brain. This would increase the temperature of the brain and leads to pathological effect $[1,2,12,14]$. The appearance of this frequency oscillations $(0.033 \mathrm{~Hz})$ of thermo-regulatory control system in auto-power spectra indicates the effect of microwave irradiation on thermo-regulatory control system of cats. Actually, Sayers [11] demonstrated the independence of thermoregulatory oscillation from the blood pressure control oscillation (Herring-Traube oscillations). Kitney [12] showed the influence of thermo-regulatory oscillations in power spectra of HRV signal or peripheral blood flow with the same influence of thermo-regulatory oscillations in blood pressure signals. Looking to Figure 4, which shows the auto-power spectrum after 15 minutes recovery period, it is obvious the disappearance of distinct peaks at $0.033 \mathrm{~Hz}$ which indicates that 15 minutes recovery period of microwave exposure, the change of HRV auto-power spectrum of HRV signal is not permanent. This finding may be significant for knowing the physiological effect of the use of cellular or mobile telephone on the body and specially on the brain [20-33].

In summary, using cell telephone by children had significant on power spectra of HRV signal. The techniques that have been developed in our laboratory to measure HRV signals may be used to include other body signals such as blood pressure and peripheral blood flow signals to evaluate potential effect of microwave exposure with different microwave power and frequencies on body control mechanism. Future study may be needed to increase the time of exposure of microwave radiation to children with different ages.

\section{References}

1. Olsen RG, Lin LC (1983) Microwave induced pressure mammalian brains. IEEE Trans $B M E$ 30: 289-294. [Crossref]

2. Lin JC (1978) Microwave auditory effect and application. Springfield, IL: Charles C Thomas.

3. Guy AW, Chou CK, Lin JC, Christensen D (1975) Microwave-induced acoustic effects in mammalian auditory systems and physical materials. Ann N Y Acad Sci 247: 194 218.[Crossref]

4. Lin JC (1980)The microwave auditory phenomenon. Proc IEEE 68: 67-73.

5. Gevins AS (1984) Analysis of the electromagnetic signals of the human brain milestones, obstacles, and goals. IEEE Trans Biomed Eng 31: 833-850.[Crossref]

6. Berman E, Chacon L, House D, Koch BA, Koch WE, et al. (1990) Development of chicken embryos in a pulsed magnetic field. Bioelectromagnetics 11: 169-187. [Crossref]

7. Koch WE, Koch BA (1991) Exposure of chicken embryos to selected fields. J Bioelec 10: $65-80$.

8. Jauchen JR (1997) Exposure to extremely low frequency electromagnetic fields and radio frequency radiation: Cardiovascular effects in humans. Int Arch Occup Environ Health 70: 9-21. [Crossref]

9. Jauchem JR, Frei MR (1994) Cardiorespiratory changes during microwave-induced lethal heat stress and beta-adrenergic blockade. J Appl Physiol 77: 434-440.[Crossref]

10. Pething P (1984) Dielectric properties of biological materials: Biophysical and medical applications. IEEE Trans Elec Insul 19: 435-474.

11. Sayers BM (1973) Analysis of heart rate variability. Ergonomics 16: 17-32.[Crossref]

12. Kitney RI, Rompelman O (1980) The study of heart rate variability, Oxford, Oxford University Press, 1980

13. Kamal A, Harness JB, Mearns AJ (1982) Respiratory control of heart rate. Euro $J$ ApplPhysiol50: 95-104

14. Kamal A, Harness JB and Mearns AJ (1983) Posture entrainment. Automedica 4: 193 200.

15. Chess GF, Tam RM, Calaresu FR (1975) Influence of cardiac neural inputs on rhythmic 


\section{variations of heart period in the cat. Am J Physiol 228: 775-780.[Crossref]}

16. Kamal A (1995) Assessment of autonomic function using complex demodulation and posture entrainment techniques: an application to normal subjects and diabetic patients. Front Med Biol Eng 7: 1-10. [Crossref]

17. Appel ML, Saul JP, Berger RD, Cohen RI (1990) Closed loop identification of cardiovascular regulatory mechanisms. Comput Cardiol 16: 3-8.

18. Glass L (1990) Is cardiac chaos normal or abnormal. $J$ Cardiovasc Electrophysiol 1: 481-482.

19. Chon KH1, Chen YM, Holstein-Rathlou NH, Marmarelis VZ (1998) Nonlinear system analysis of renal autoregulation in normotensive and hypertensive rats. IEEE Trans Biomed Eng 45: 342-353.[Crossref]

20. Haarala C, Bjorn erg L, Ek M, Laine M, Revonsuo A, et al. (2003) Effect of a 902 $\mathrm{MHz}$ electromagnet field emitted by mobile phones on human Cognitive function: A replication study. Bioelectromagnetics 24: 283-288. [Crossref]

21. CENELEC (2001) European Committee for ElectrotechnicalStandardization.Product standard to demonstrate the compliance of mobile phones with the basic restrictions related to human exposure to electromagnetic fields ( $300 \mathrm{MHz}-\mathrm{GHz})$.

22. Nolte J (2002) The Human Brain. An Introduction to its Functional Anatomy, (5thedn), Mosby: St Louis.

23. Eliyahu I, Luria R, Hareuveny R, Margaliot M, Meiran N, et al. (2006) Effects of radiofrequency radiation emitted by cellular telephones on the cognitive functions of humans. Bioelectromagnetics 27: 119-126. [Crossref]

24. Anderson V, Rowley J (2007) Measurements of skin surface temperature during mobile phone use. Bioelectromagnetics 28: 159-162.[Crossref]
25. Lin JC (2005) A Microwave Induced Blood Brain Barrier Permeability Changes in Laboratory Rats@ (Invited) URSI General Assembly, New Dehli, India, October.

26. Lin JC (2005) "Health Aspects of Solar Power Satellite Associated Microwave Power Transmission “(Invited) URSI General Assembly, New Dehli, India, October.

27. Lin JC (2006) The Establishment and Promulgation of Radio-frequency Exposure Guidelines for Health Protection,@ (Invited Plenary Lecture) Values in Decisions on Risk (VALDOR) Symposium, Stockholm, May.

28. Bernardi P, Cavagnaro M, Pisa S, Piuzzi E, Lin JC (2007) "Exposure of Adult and Child-Scaled Human Body Model at Mobile Communication Systems Frequencies" 11th International Symposium on Microwave and Optical Technology (ISMOT 2007) Rome, Italy, Dec.

29. Lin JC (2008) "Microwave Techniques for Interstitial Ablation and Hyperthermia" (Invited) Bioelectromagnetics Society Winter Workshop, Washington DC, Feb.

30. Lin JC (2008) "Issues for Considerations for Future RF Exposure Standards," (Invited) 30th Annual Mtg. Bioelectromagnetics Soc. San Diego, CA, June.

31. Lin JC (2009) "Long Term Health Effects of Cell Phone Use: Biological Effects and Health Implications of Cellular Mobile Communication Radiation," (Invited) AALAS District 6 Meeting, Rosemont, Illinois, September.

32. Lin JC (2009) "Noninvasive and remote wireless sensing of physiologic signatures and vital signals" (Invited Distinguished Lecture), XVII Argentinean Congress on Bioengineering, Rosario, Argentina. October.

33. Lin JC (2010) "RF Exposure Standards, Guidelines and Their Rationale" (Invited) International Conference of Radio communication on Health and Environment Prospective, Muscat, Sultanate of Oman, January.

Copyright: $\odot 2016 \mathrm{Kamal}$ AK. This is an open-access article distributed under the terms of the Creative Commons Attribution License, which permits unrestricted use, distribution, and reproduction in any medium, provided the original author and source are credited. 